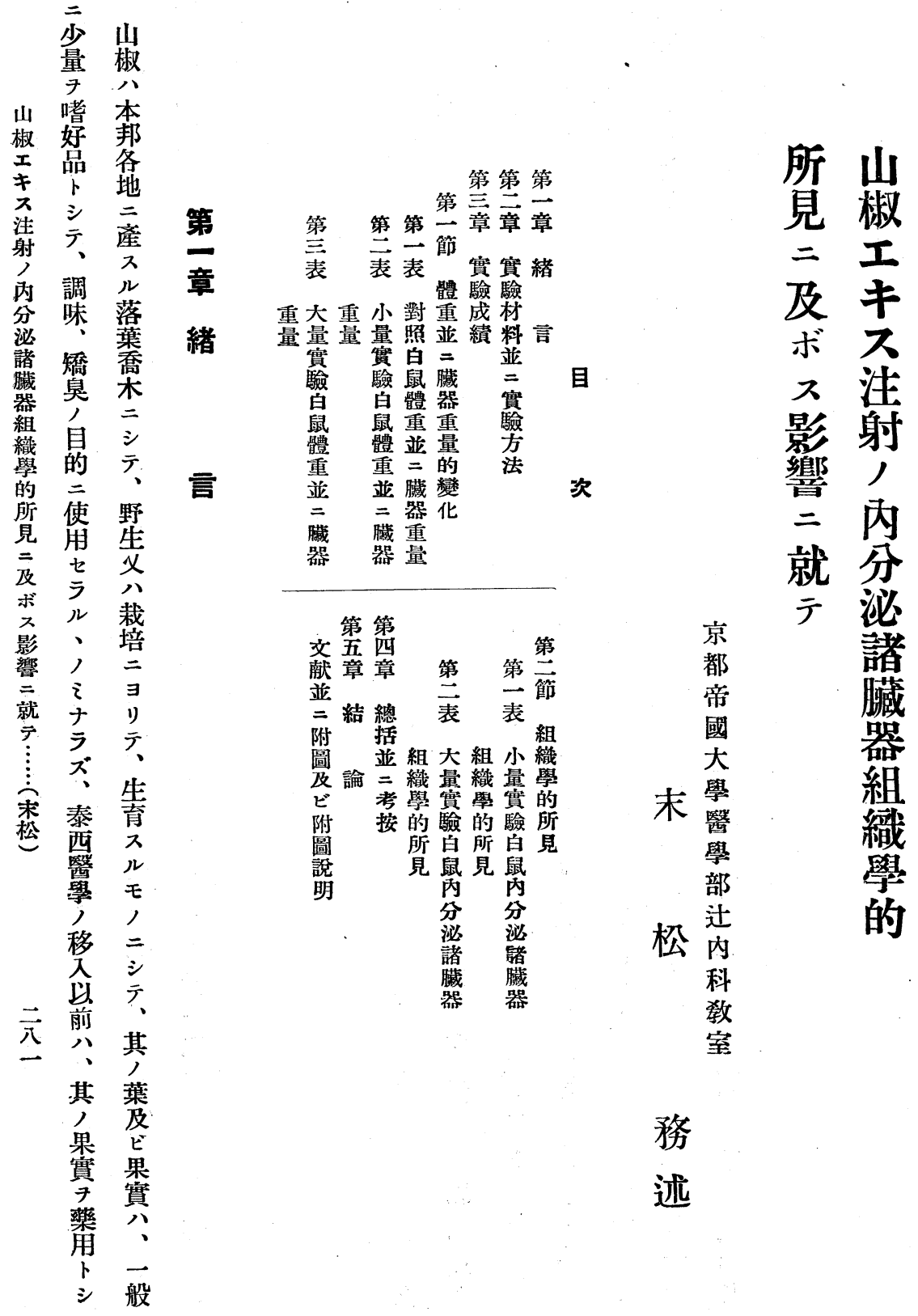




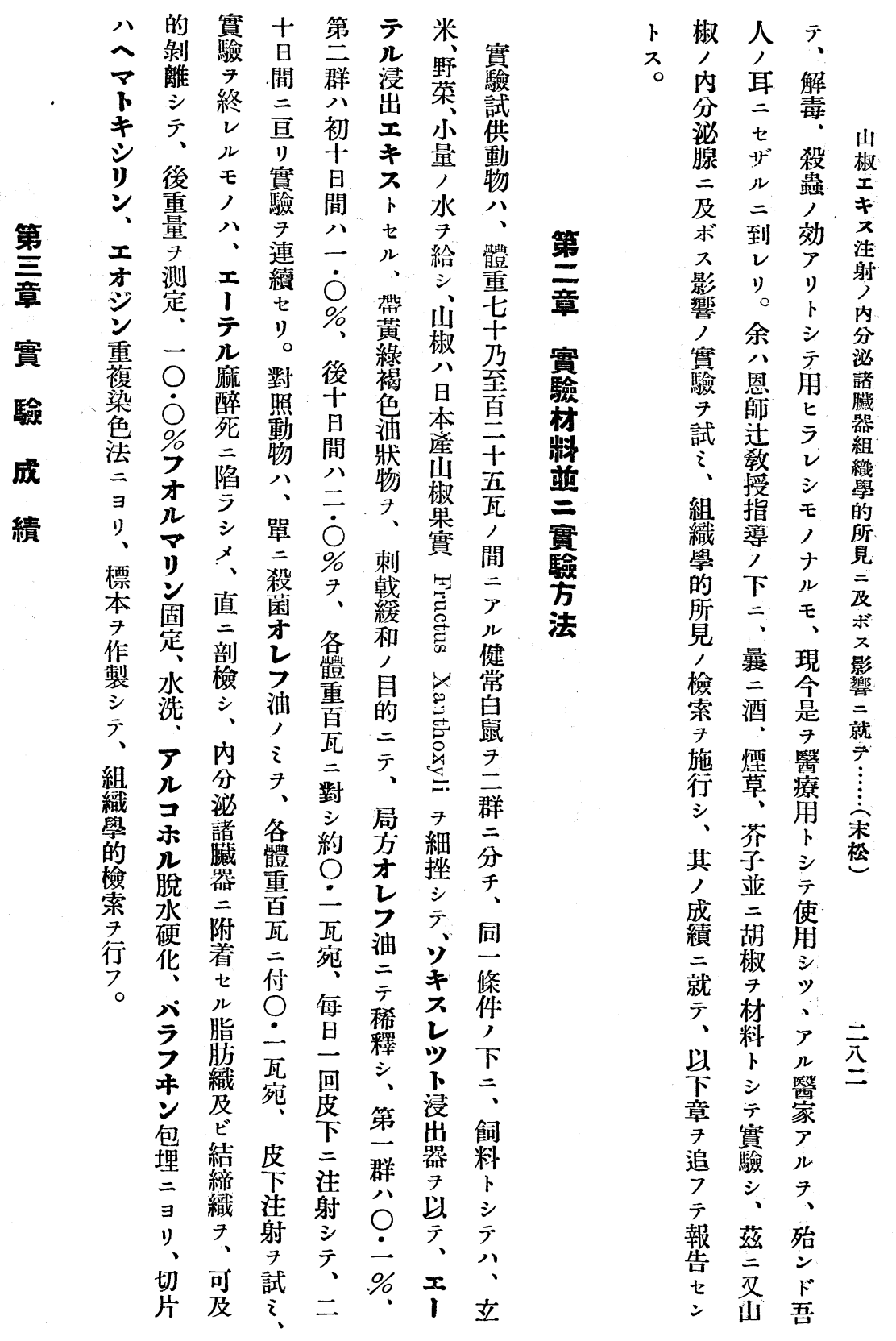




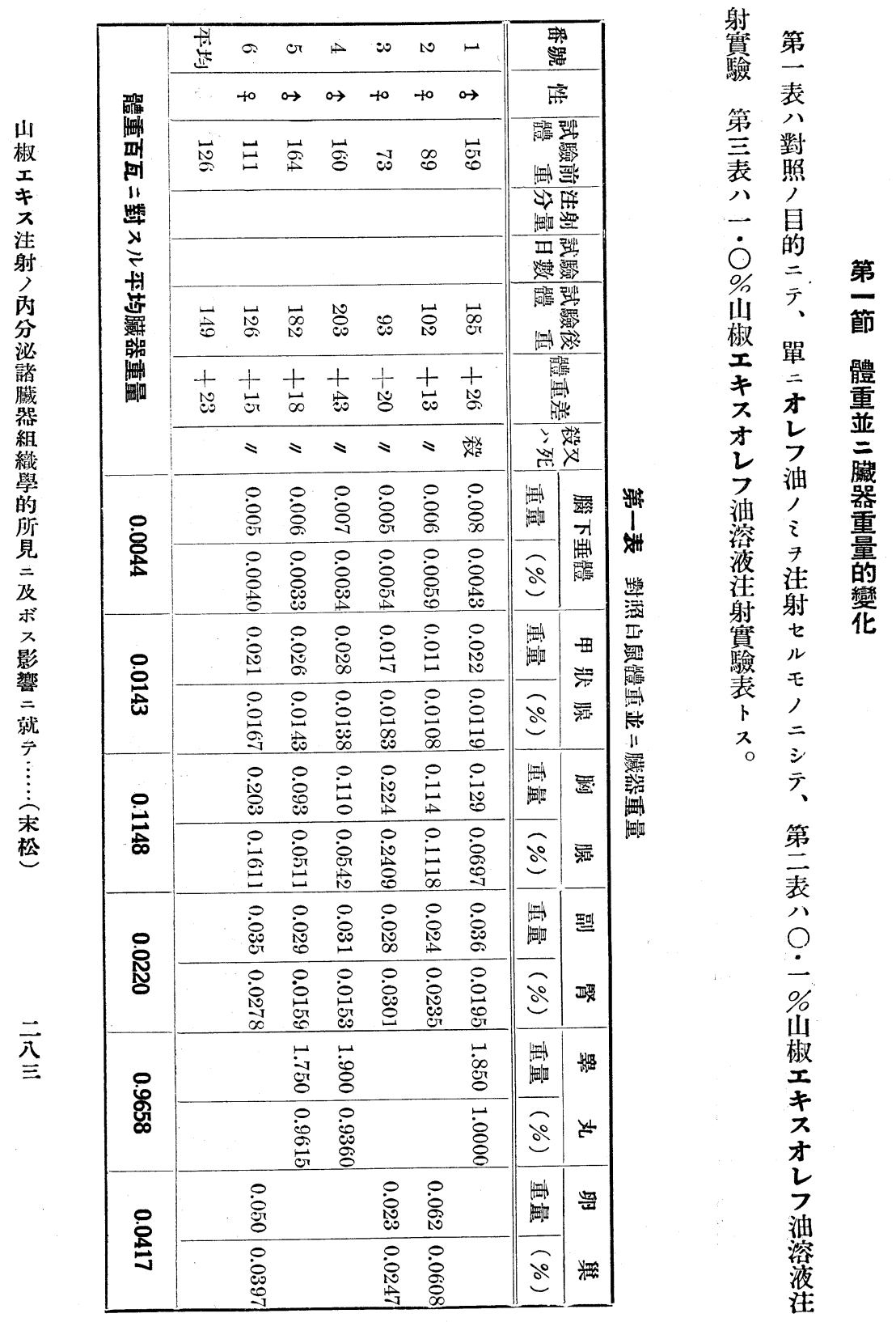




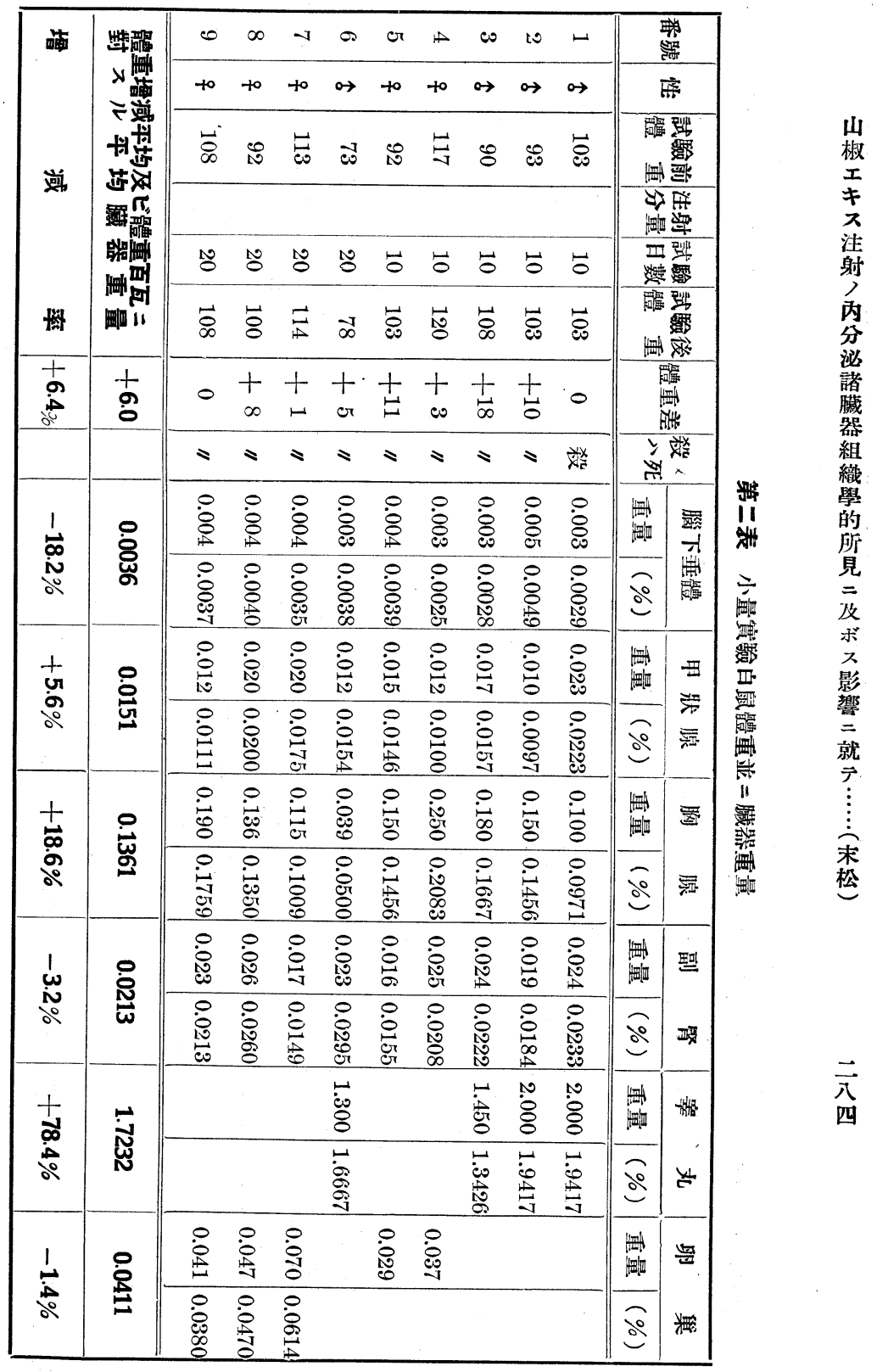




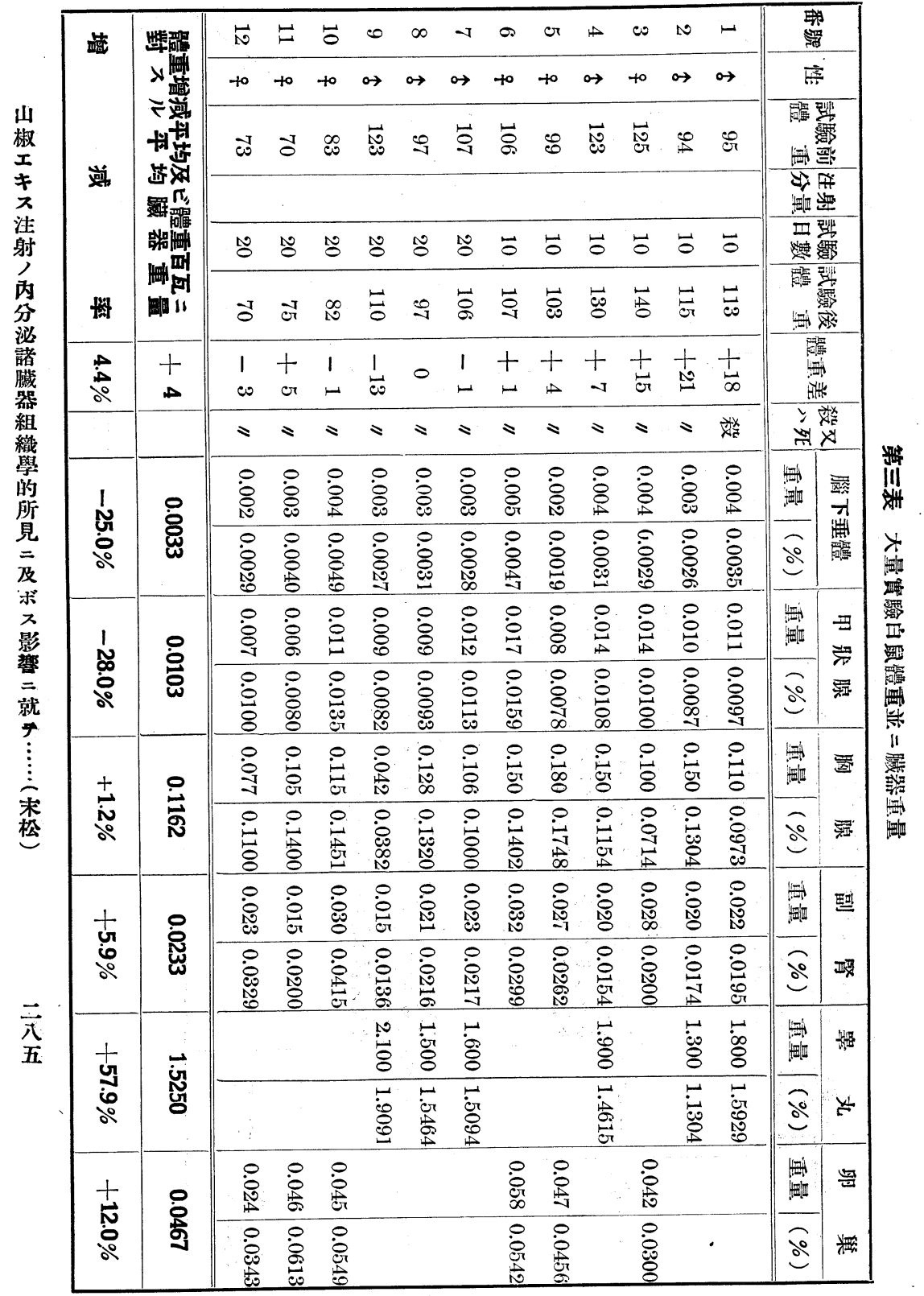




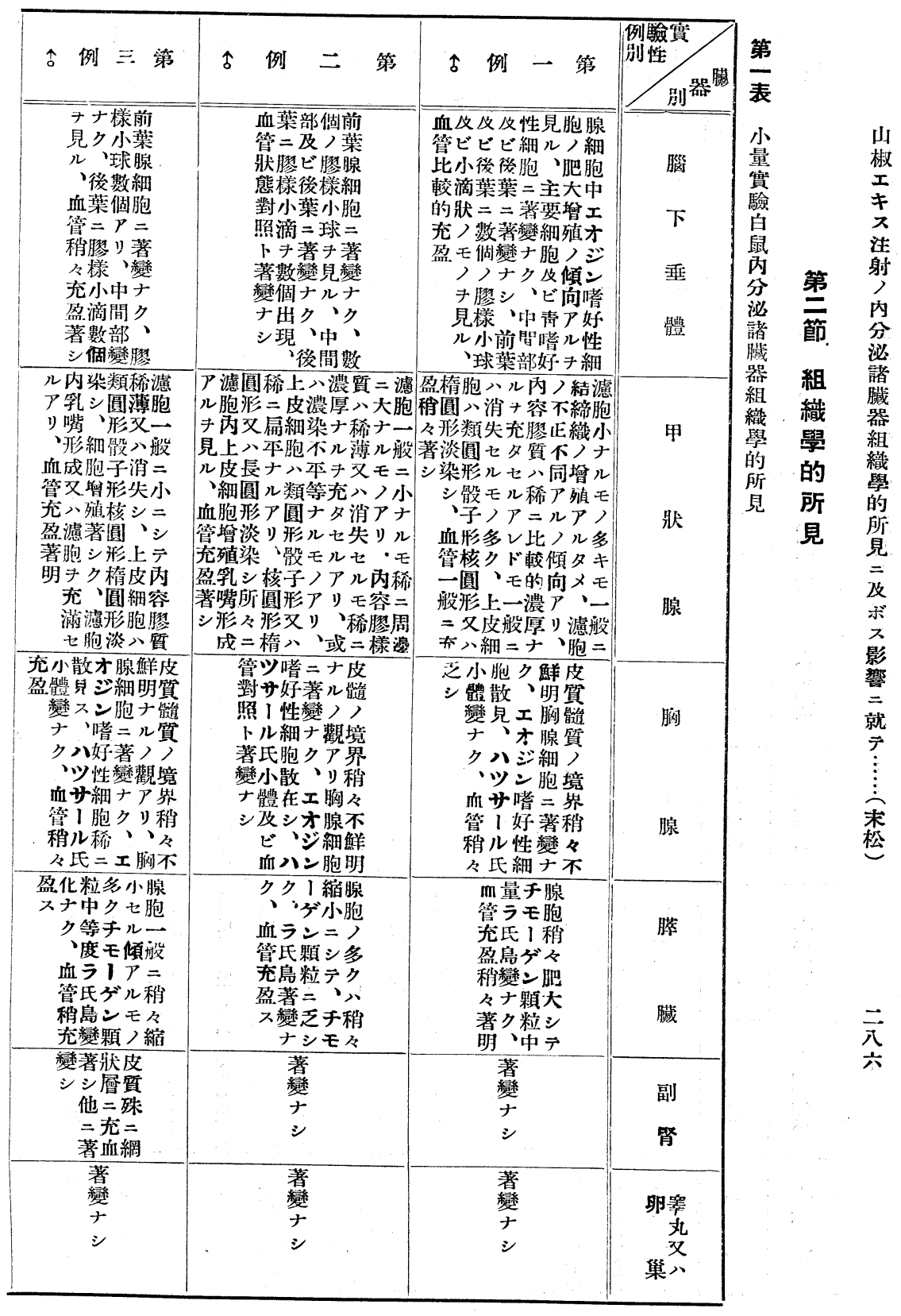




\begin{tabular}{|c|c|c|c|}
\hline 古 例 七 第 & 例 共 第 & ㅇ 例 五 第 & 古例四籍 \\
\hline 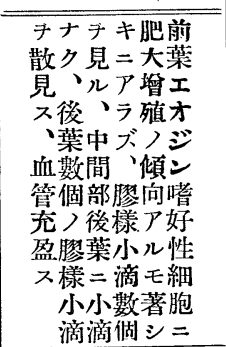 & 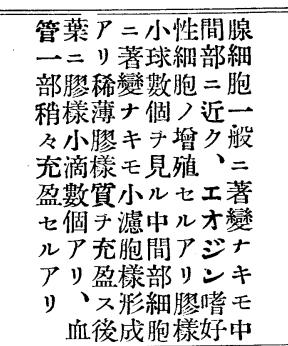 & 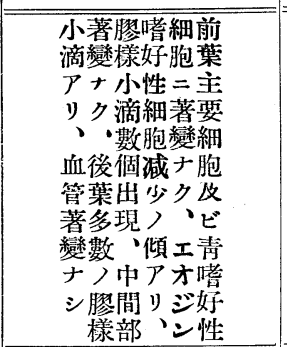 & 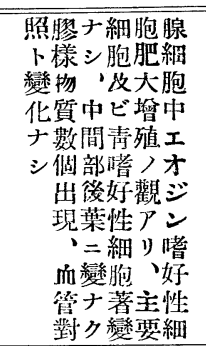 \\
\hline 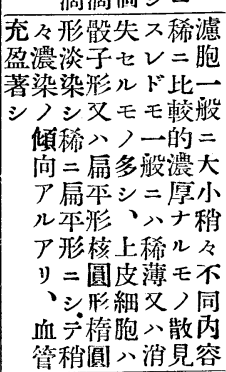 & 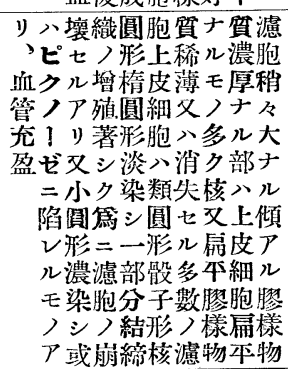 & 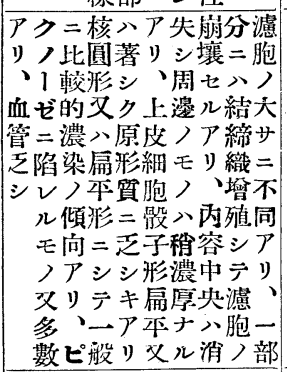 & 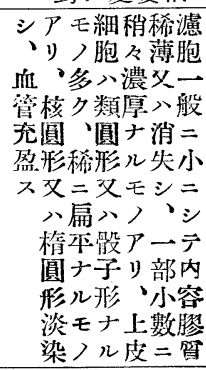 \\
\hline 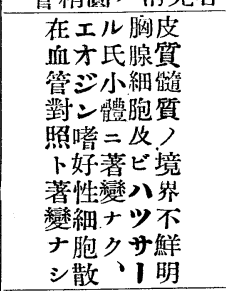 & 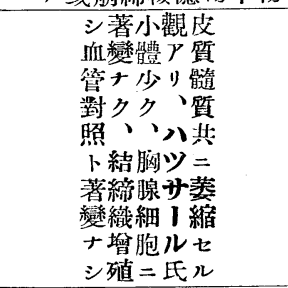 & 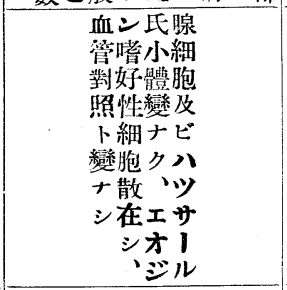 & 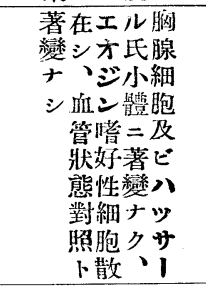 \\
\hline 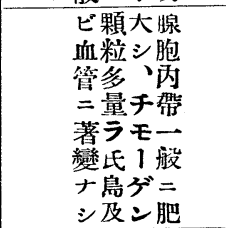 & 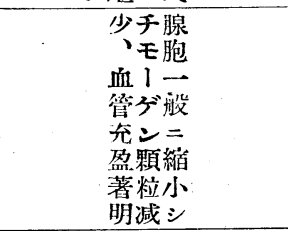 & 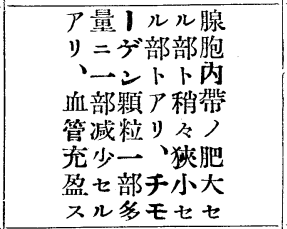 & 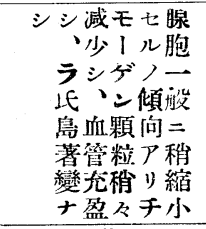 \\
\hline $\begin{array}{l}\text { 著 } \\
\text { 變 } \\
\text { ナ } \\
\text { シ }\end{array}$ & $\begin{array}{l}\text { 著 } \\
\text { 變 } \\
\text { ナ } \\
\text { シ }\end{array}$ & $\begin{array}{l}\text { 著 } \\
\text { 戀 } \\
\text { ナ } \\
\text { シ }\end{array}$ & $\begin{array}{l}\text { 著 } \\
\text { 變 } \\
\text { ナ } \\
\text { シ }\end{array}$ \\
\hline $\begin{array}{l}\text { 著 } \\
\text { 變 } \\
\text { ナ } \\
\text { シ }\end{array}$ & 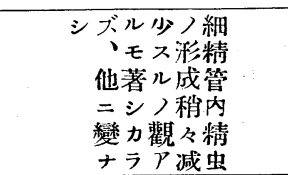 & $\begin{array}{l}\text { 著 } \\
\text { 變 } \\
\text { ナ } \\
\text { シ }\end{array}$ & $\begin{array}{l}\text { テク血 } \\
\text { シ管 } \\
\text { 他充 } \\
\text { 二盈 } \\
\text { 變著 } \\
\text { 化シ }\end{array}$ \\
\hline
\end{tabular}




\begin{tabular}{|c|c|c|c|c|c|}
\hline 占 例 一 第 & 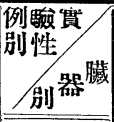 & $\frac{\text { 第 }}{\frac{\overline{\bar{k}}}{\mathbf{n}^{2}}}$ & 古 例 九 第 & 古 例 八 第 & $\begin{array}{l}\text { 例驗賽 } \\
\text { 别器臟 }\end{array}$ \\
\hline 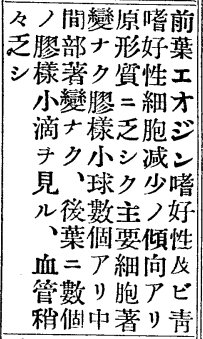 & $\begin{array}{l}\text { 腦 } \\
\text { 下 } \\
\text { 垂 } \\
\text { 體 }\end{array}$ & $\begin{array}{l}\text { 大 } \\
\text { 量. } \\
\text { 㥶 } \\
\text { 驗 } \\
\text { 白 } \\
\text { 鼠 } \\
\text { 䏌 } \\
\text { 分 } \\
\text { 㳴 } \\
\text { 諸 } \\
\text { 藏 }\end{array}$ & 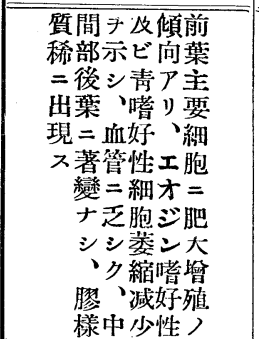 & 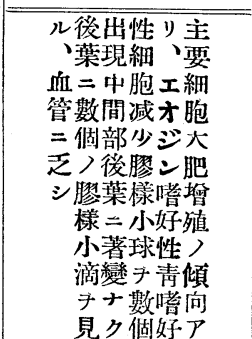 & $\begin{array}{l}\text { 腦 } \\
\text { 下 } \\
\text { 垂 } \\
\text { 體 }\end{array}$ \\
\hline 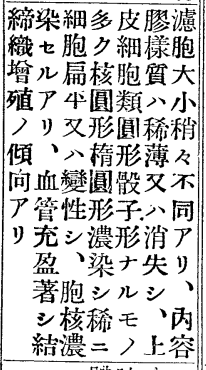 & 狀 & $\begin{array}{l}\text { 緗 } \\
\text { 織 } \\
\text { 學 } \\
\text { 的 } \\
\text { 所 } \\
\text { 見 }\end{array}$ & 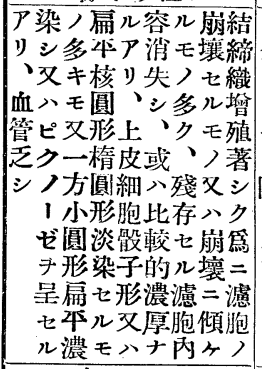 & 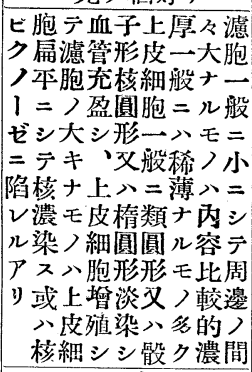 & 狀 \\
\hline 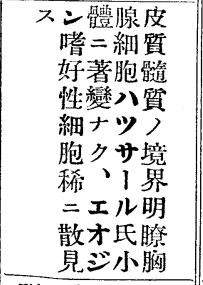 & 胸 & & 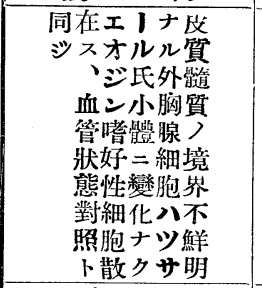 & 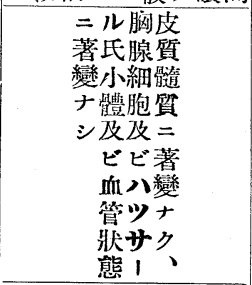 & 腺 \\
\hline 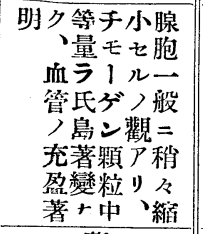 & 臟 & & 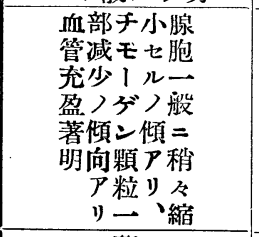 & 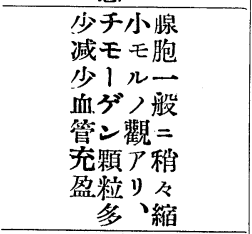 & 臟 \\
\hline 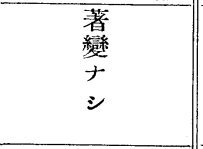 & 㛑 & & $\begin{array}{l}\text { 著 } \\
\text { 戀 } \\
ナ \\
\text { ン }\end{array}$ & $\begin{array}{l}\text { 二充皮 } \\
\text { 著盈質 } \\
\text { 變著血 } \\
\text { ナシ管 } \\
\text { シ他〉 }\end{array}$ & $\begin{array}{l}\text { 副 } \\
\text { 腎 }\end{array}$ \\
\hline $\begin{array}{l}\text { 著 } \\
\text { 變 } \\
ナ \\
\text { シ }\end{array}$ & 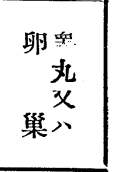 & & $\begin{array}{l}\text { ナ明血 } \\
\text { シナ管 } \\
\text { ル充 } \\
\text { 外盈 } \\
\text { 著ノ } \\
\text { 變著 } \\
\end{array}$ & $\begin{array}{l}\text { 他血 } \\
\text { 管 } \\
\text { 著充 } \\
\text { 變盈 } \\
\text { ナ著 } \\
\text { シ明 }\end{array}$ & 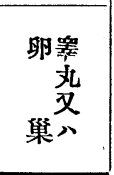 \\
\hline
\end{tabular}









\begin{tabular}{|c|c|c|c|}
\hline 例 八 第 & 例 七 第 & 例 & \\
\hline 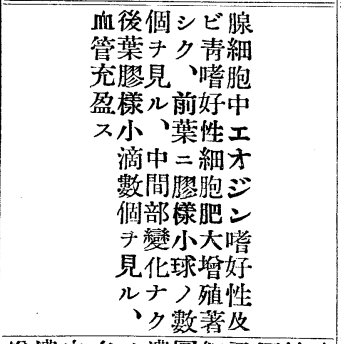 & 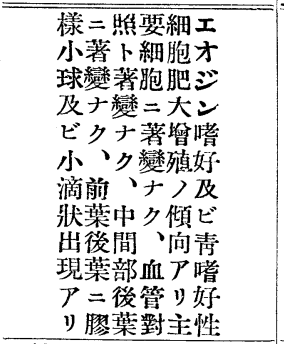 & 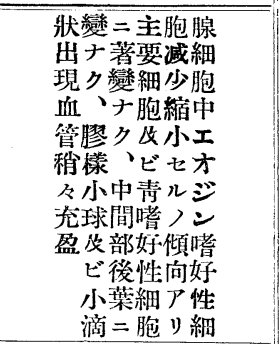 & $\begin{array}{l}\text { 下 } \\
\text { 垂 } \\
\text { 體 }\end{array}$ \\
\hline 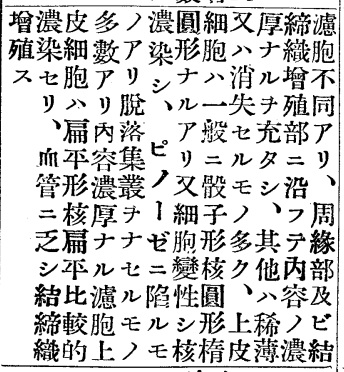 & 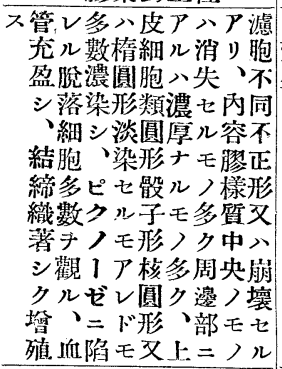 & 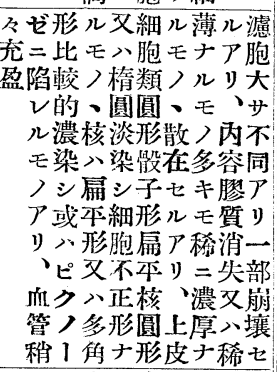 & 狀 \\
\hline 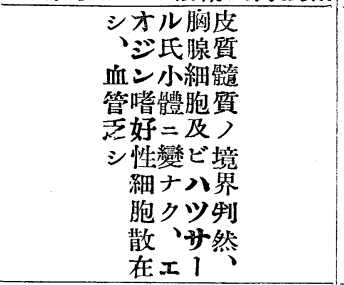 & 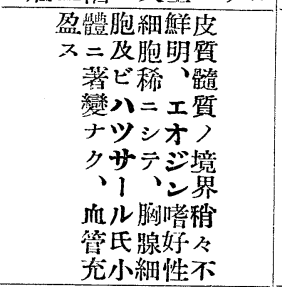 & 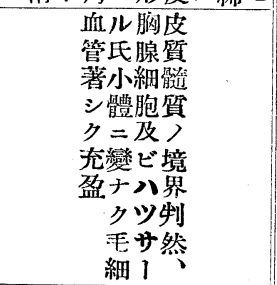 & 腺 \\
\hline 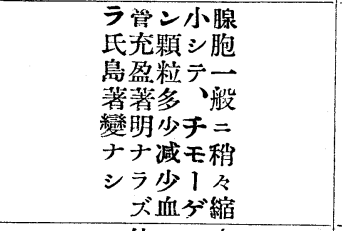 & $\begin{array}{l}\text { 島多顆小腺 } \\
\text { 著ク粒シ胞 } \\
\text { 變血减テー } \\
\text { ナ管少チ般 } \\
\text { シ文七モ二 } \\
\text { ビル I稍 } \\
\text { ラモぶ々 } \\
\text { 氏ノン縮 } \\
\end{array}$ & 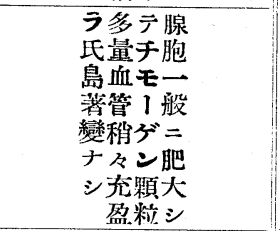 & 臟 \\
\hline $\begin{array}{c}\text { シ他シ二皮 } \\
=キ \text { 充啠 } \\
\text { 著ア血ノ } \\
\text { 變ルノ一 } \\
\text { ナモ著部 }\end{array}$ & 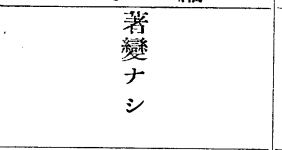 & 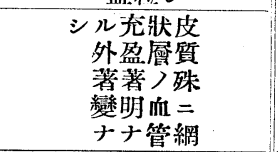 & $\begin{array}{l}\text { 副 } \\
\text { 腎 }\end{array}$ \\
\hline 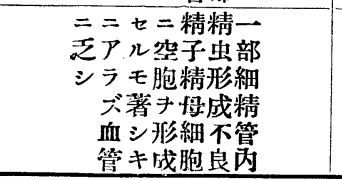 & $\begin{array}{l}\text { 著 } \\
\text { 變 } \\
\text { ナ } \\
\text { シ }\end{array}$ & $\begin{array}{l}\text { 著 } \\
\text { 變 } \\
ナ \\
\text { シ }\end{array}$ & 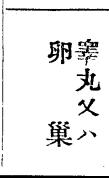 \\
\hline
\end{tabular}




\begin{tabular}{|c|c|c|c|}
\hline \& 例二十第 & 例一十第 & 十 節 & 占 例 元 第 \\
\hline 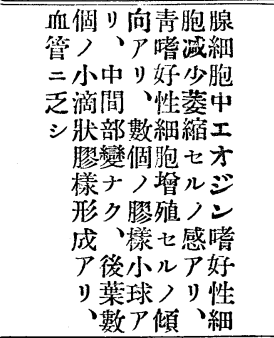 & 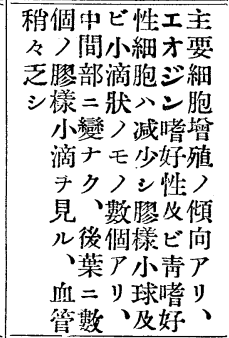 & 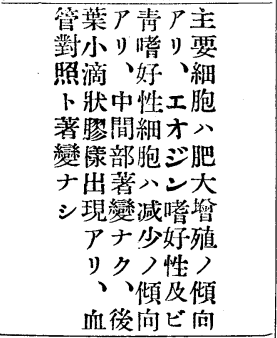 & 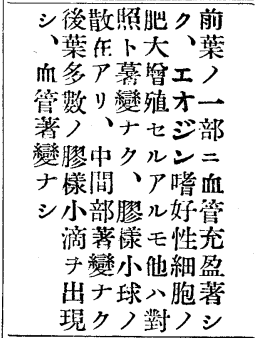 \\
\hline 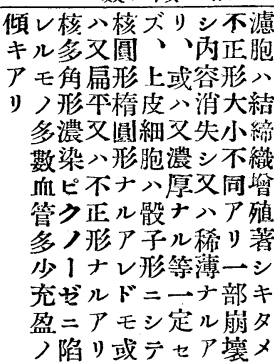 & 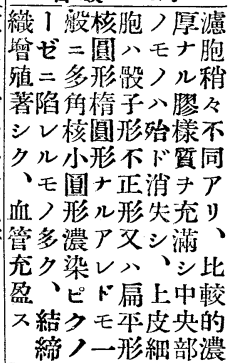 & 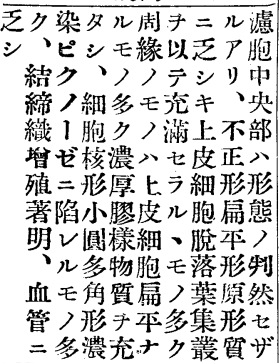 & 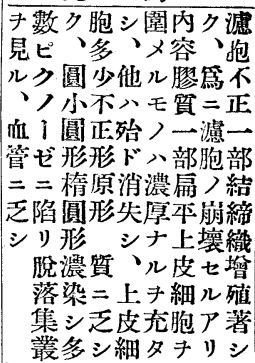 \\
\hline 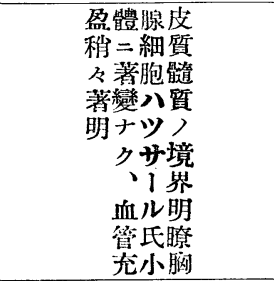 & 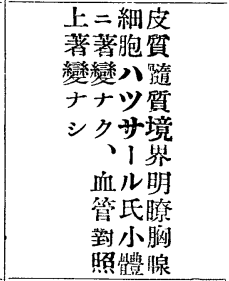 & 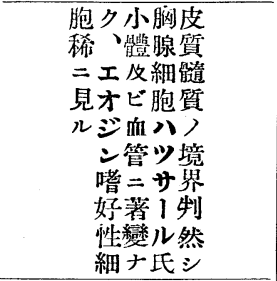 & 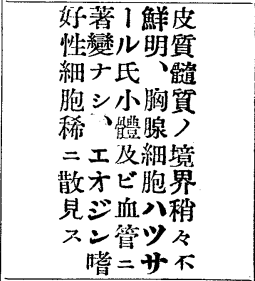 \\
\hline 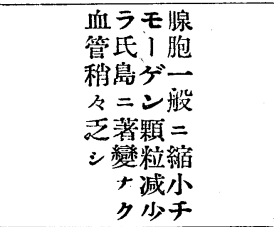 & 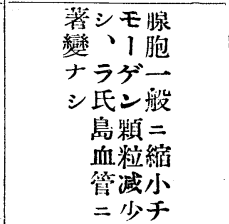 & 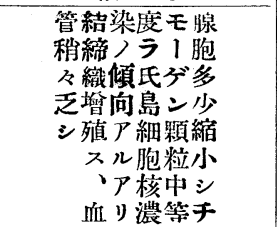 & 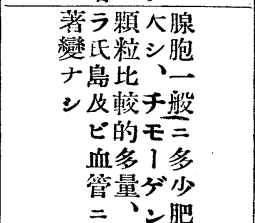 \\
\hline $\begin{array}{l}\text { 㝨及皮 } \\
\text { 戀著嗳 } \\
\text { ナシ充 } \\
\text { シキ血 } \\
\text { 外稍 }\end{array}$ & $\begin{array}{l}\text { 萻 } \\
\text { 變 } \\
\text { 到 }\end{array}$ & $\begin{array}{l}\text { 萻 } \\
\text { 變 } \\
\text { 严 }\end{array}$ & 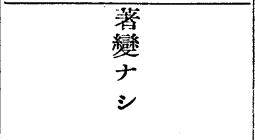 \\
\hline 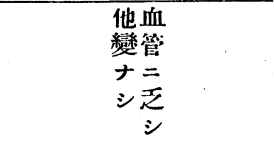 & 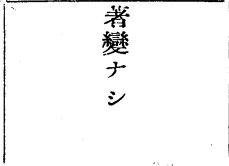 & 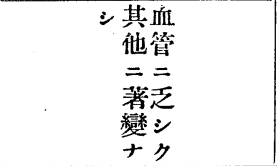 & $\begin{array}{l}\text { 血著管變 } \\
\text { 淁シ }\end{array}$ \\
\hline
\end{tabular}




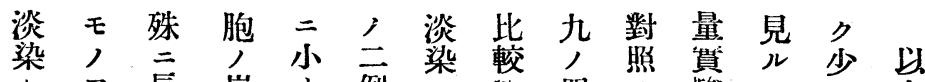
ル モド兾七モ公モ厚二三於ギ小, 多モ驗 ル 他衤多光

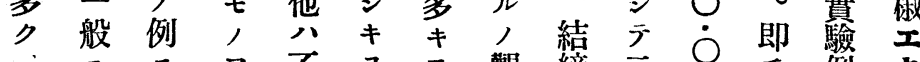

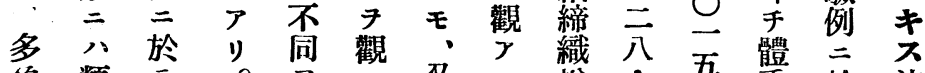

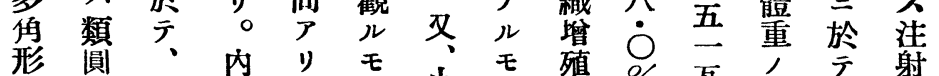

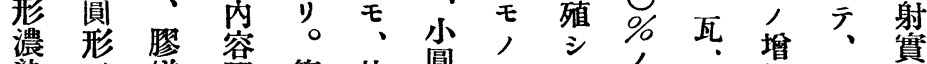

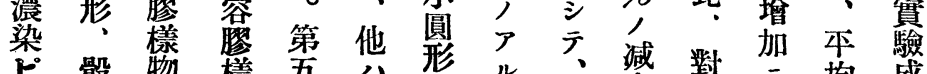

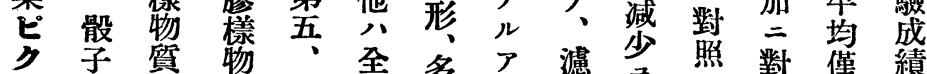

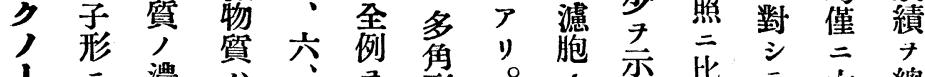

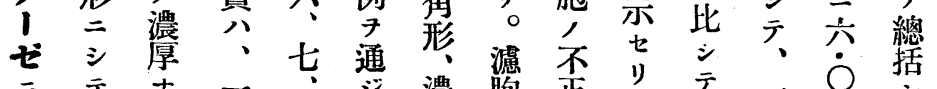

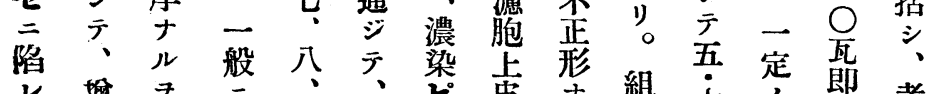

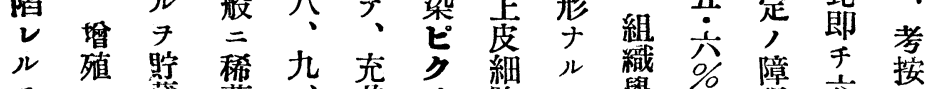

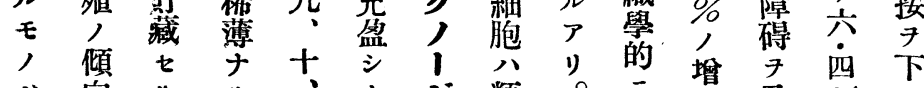

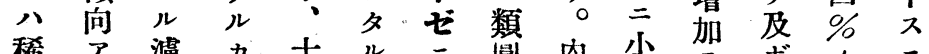

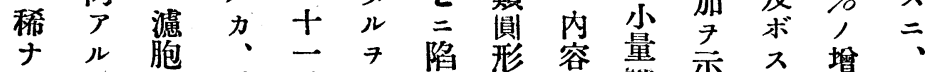

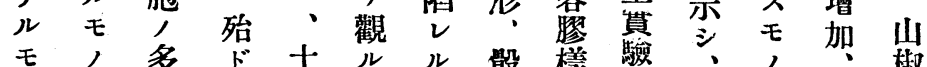

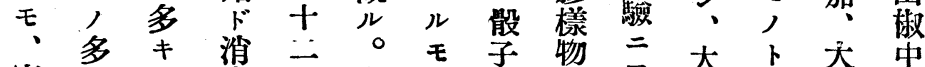

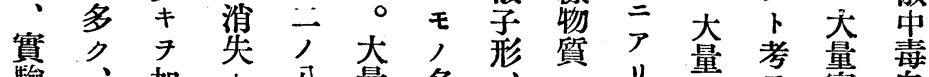

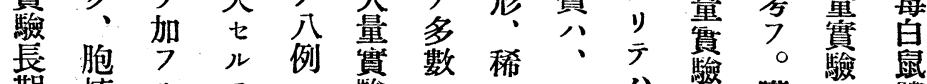
期核ル, モ モ 實傾多 :

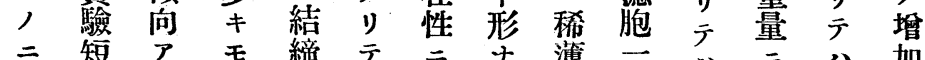

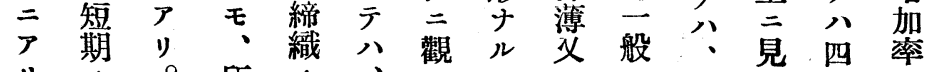

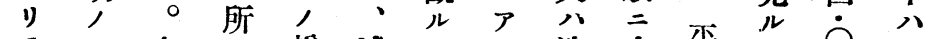

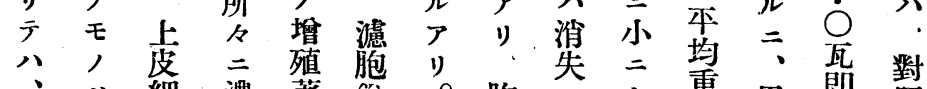

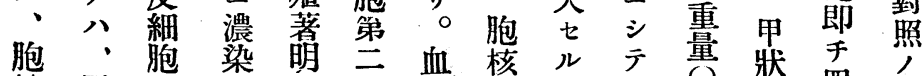

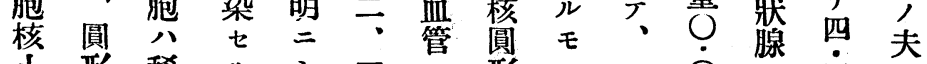
小形稀儿シ三公形, - 0 分四三 圆形扁, モ六四第楕多五 多形勇 少 


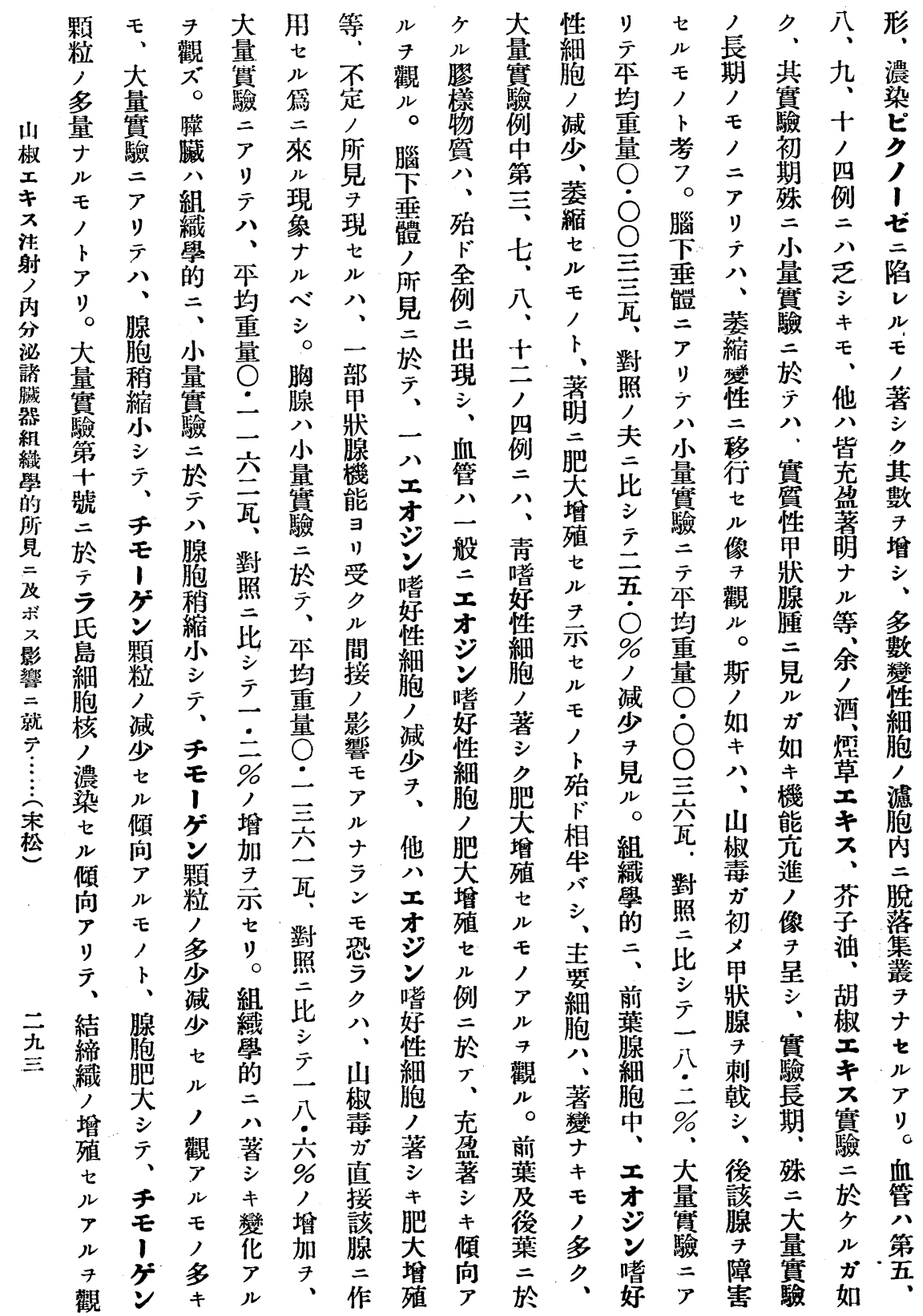




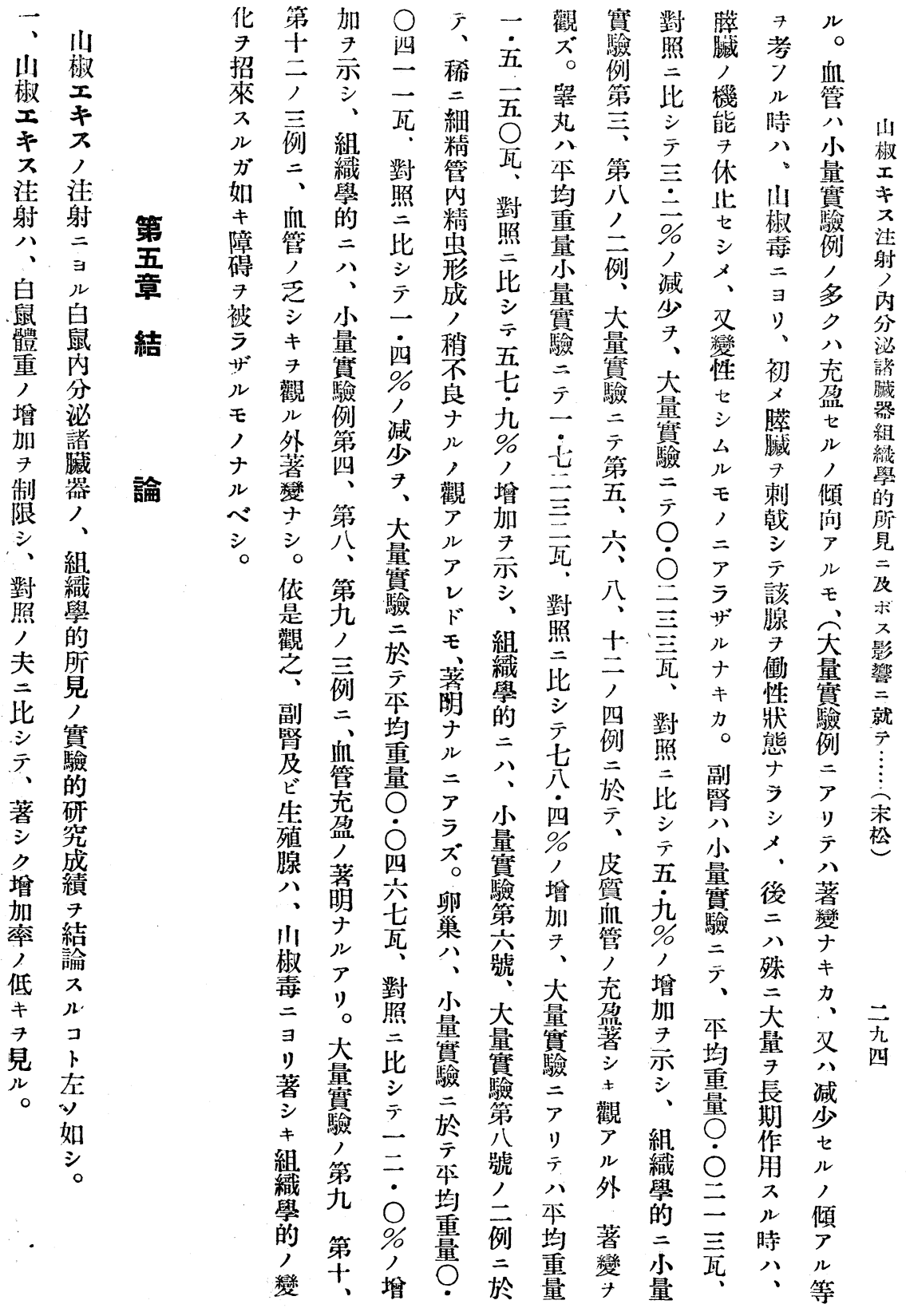




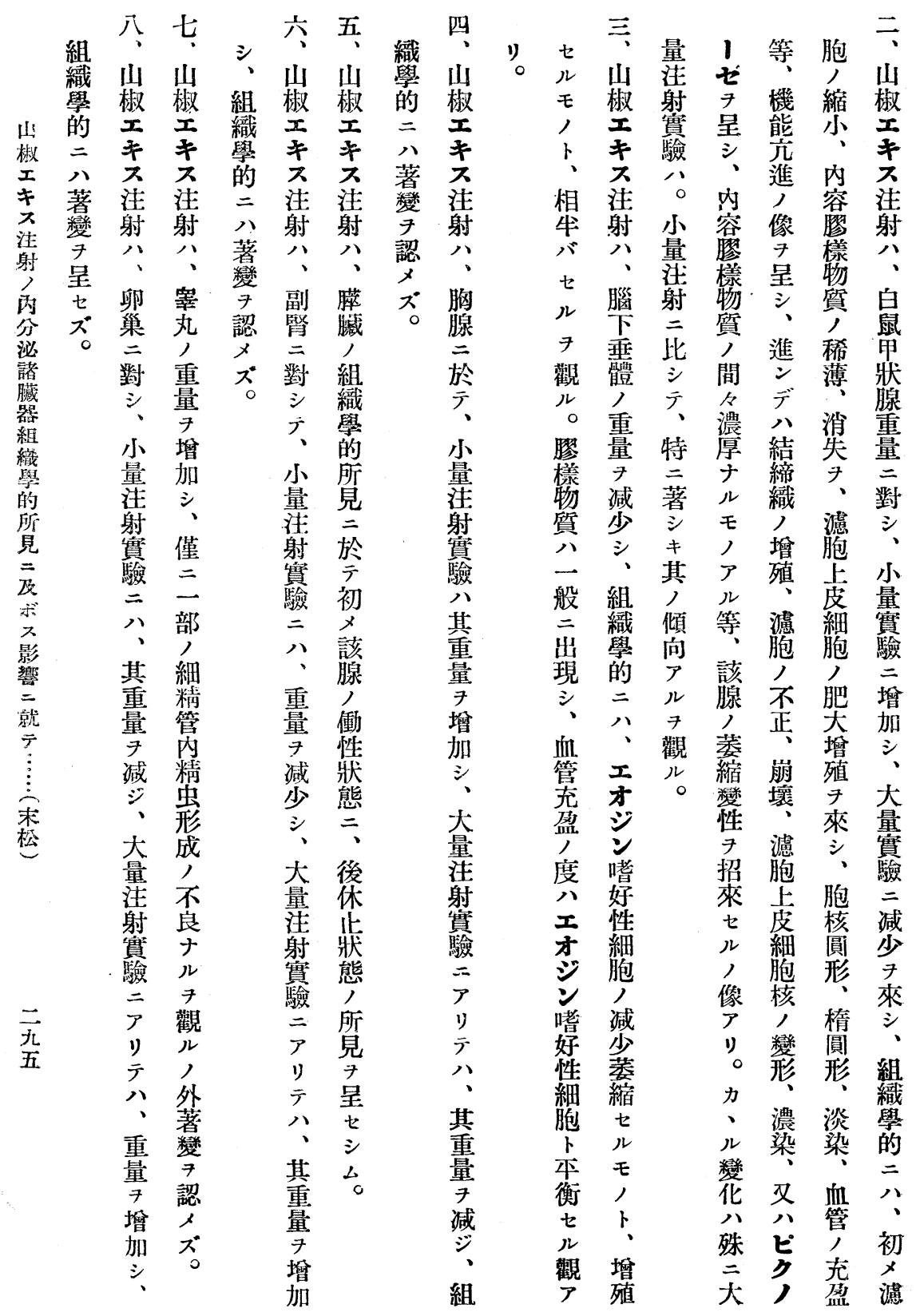




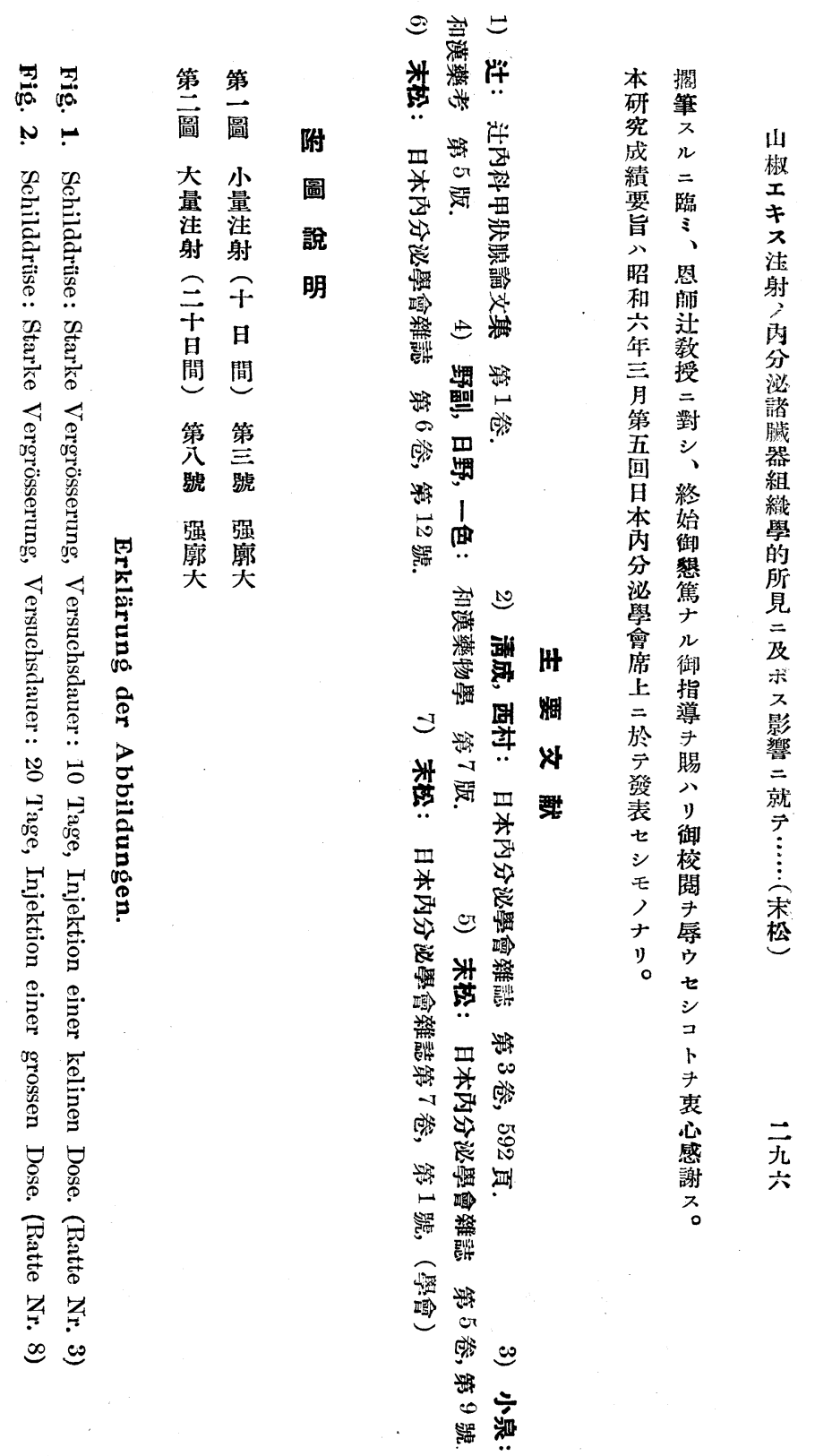



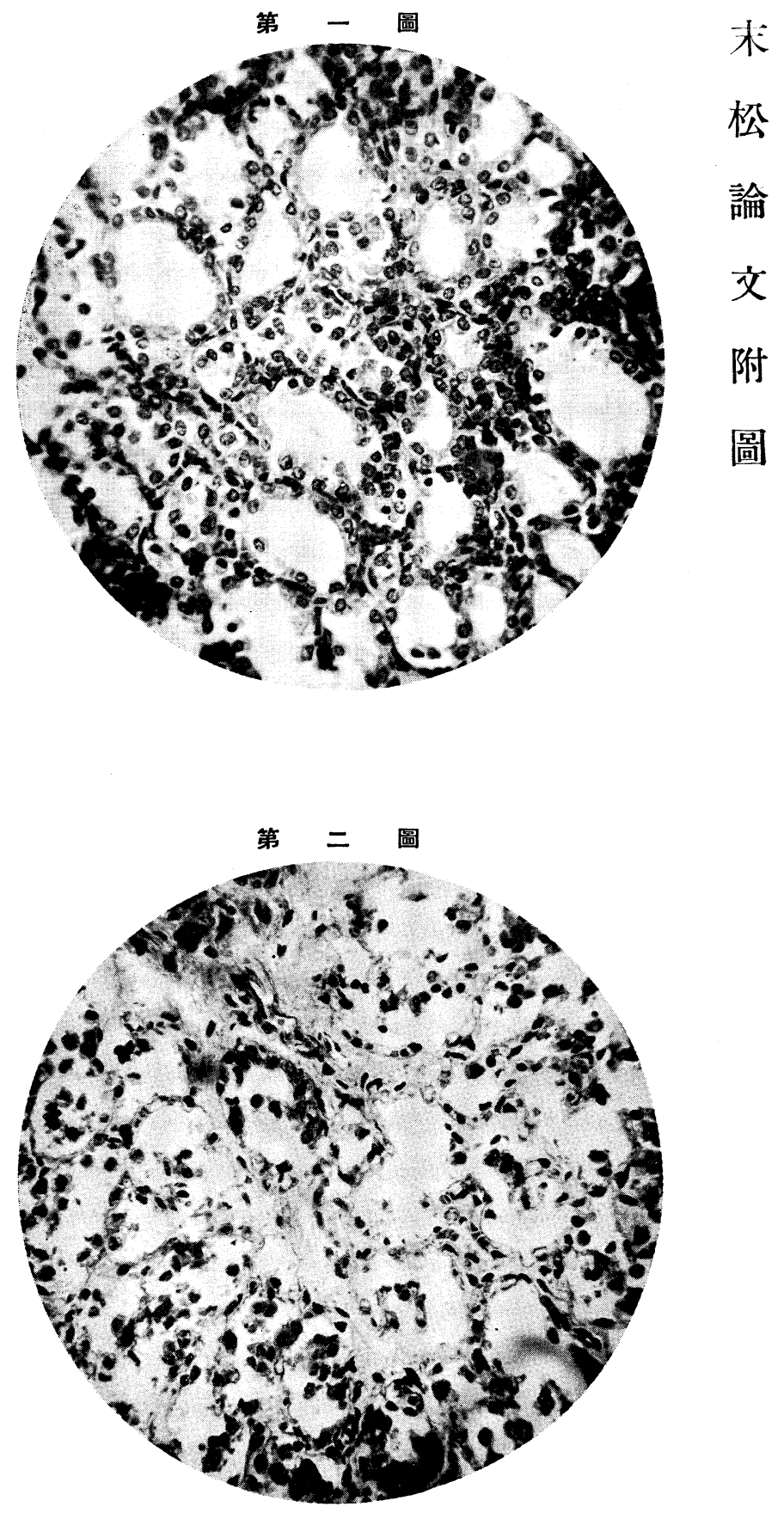
(Aus der I. med. Klinik der Kaiserlichen Universität zu Kyoto, Japan. Direktor: Prof. Dr. K. Tsuji.)

Gesunde Ratten (K. G. 70-150 g) wurden in 2 Gruppen geteilt. Der Verfasser stellte zuerst Aetherextrakt von Fructus Piperis nigri her, verdünnte diesen mit Olivenöl 0.1 u. $1.0 \%$ ig und injizierte den Ratten der einen Gruppe subkutan täglich $0.1 \mathrm{ccm}$ der $0.1 \%$ igen Lösung pro $100 \mathrm{~g}$ Körpergewicht und denen der anderen Gruppe dieselbe Menge der $1.0 \%$ igen Lösung. Die beiden Gruppen wurden nach 10 oder 20 Versuchstagen getötet und die histologischen Veränderungen der Inkretorgane untersucht.

Die Resultate waren die folgenden:

Körpergewicht und Organgewicht:

Das Körpergewicht des Versuchstieres nahm im allgemeinen ab. Schilddrüse, Nebenniere und Geschlechtsdrüsen nahmen an Gewicht zu, die Hypophyse dagegen ab.

Histologische Befunde:

Schilddrüse: Im Frühstadium zeigten sich kleine Follikel, Abnahme oder Verschwinden der Kolloidsubstanz, Hypertrophie und Hyperplasie der Epithelzellen, Hyperämie der Kapillargefässe, nämlich das Bild der gesteigerten Funktion der Schilddrüse, endlich aber nach längerer Zeit unregelmässige Form und Zerfall der Follikel, Zunahme der Kolloidsubstanz, regressive Veränderungen der Kerne der Epithelzellen, Wucherung des Bindegewebes, nämlich das Bild der atrophisch-degenerativen Veränderung der betreffenden Organe.

Hypophyse: Im allgemeinen vermehrten sich die eosinophilen Zellen im Vorderlappen. An Pankreas, Thymus, Nebenniere, Hoden u. Ovarium etc. sah der Verfasser keine nennenswerte Veränderung.

(Autoreferat)

\section{Ueber den Einfluss der Injektion des Extraktes \\ von Xanthoxylum piperitum D. C. auf die histologischen Veraenderungen der innersekretorischen Organe.}


Von

Dr. T. Suematsu.

(Aus der I. med. Klinik der Kaiserl. Universität zu Kyoto, Japan.

Direktor : Prof. Dr. K. Tsuji.

Die Versuchstiere (gesunde Ratten, K. G. 70-125 g) wurden in zwei Gruppen geteilt. Der Verfasser zerquetschte den japanischen Xanthoxylum und extrahierte ihn in Aether, darauf stellte er mit Olivenöl eine $0.1-1.0-2.0 \%$ ige Lösung dar und injizierte davon den Ratten der einen Gruppe jeden Tag $0.1 \mathrm{cem}$ der $0.1 \%$ igen Lösung pro $100 \mathrm{~g} \mathrm{~K}$. G. und denen der anderen Gruppe anfangs 10 'Tage lang $0.1 \mathrm{ccm}$ der $1.0 \%$ igen Lösung pro $100 \mathrm{~g} \mathrm{~K}$. G. und darauf 10 Tage lang dieselbe Menge der $2.0 \%$ igen Lösung. Die beiden Gruppen wurden nach 10 oder 20 Versuchstagen getötet und die histologischen Veränderungen der endokrinen Organe untersucht.

Die Resultate waren die folgenden :

Körpergewicht und Organgewicht :

Durch diese Injektionen nahm das Körpergewicht des Tieres nur sehr gering im Vergleich mit dem der Kontrolltiere zu. Die Hypophyse nahm an Gewicht ab, Thymus und Hoden zu, die Schilddrüsse bei der Injektion von kleinen Dosen zu, bei dem Versuch mit grossen dagegen ab, Nebenniere u. Ovarium standen hinsichtlich der Gewichtsveränderung im umgekehrten Verhältnisse zur Schilddrüse.

Histologische Befunde:

Die Schilddrüse zeigte im Anfangsstadium das Bild der Hyperfunktion (kleine Follikel, Abnahme oder Verschwinden der Kolloidsubstanz, starke Hypertrophie und Hyperplasie der Epithelzellen mit grösserem rundlichem oder ovalem, dünn gefärbtem Kerne, Hyperämie der Kapillargefässe usw.). Aber im Endstadium, besonders bei der Injektion mit grossen Dosen, fand sich das Bild der Hypofunktion der Schilddrüse (unregelmässige Form bzw. Zerfall der Follikel, Zunahme der Kolloidsubstanz, starke Wucherung des Bindegewebes, Degeneration der Epithelzellen mit pyknotischen Kernen usw.). Ton 
den chromophilen Zellen im Vorderlappen der Hypophyse zeigten manche Verminderung und Verkleinerung, andere dagegen Vermehrung und Hypertrophie. Bei allen Fällen trat deutlich im Vorderund Hinterlappen der Hypophyse Kolloidsubstanz auf. An Thymus, Pankreas und Genitaldrüse sah der Verfasser keine nennenswerte Veränderungen.

(Autoreferat)

\title{
Ueber den Einfluss der Lichtabhaltung auf die Regenerationsvorgänge des Blutes und die Wirkung der Schilddrüsenexstirpation darauf.
}

\author{
Von
}

Dr. S. Tasaka.

(Aus der I. med. Klinik der Kaiserlichen Universität zu Kyoto, Japan. Direktor : Prof. Dr. K. Tsuji.')

An eine bestimmte Zeit lang im Dunkel gehaltenen ausgewachsenen Kaninchen wurden die Regenerationsvorgänge des Blutes und der Einfluss der Schilddrüsenexstirpation darauf verfolgt.

Die Resultate lassen sich kurz wie folgt zusammenfassen.

1) Durch die kurzdauernde Lichtabhaltung vermindern sich vorübergehend in sehr leichtem Grade der Hb-gehalt und die Erythrocytenzahl. Diese Verminderung macht im Laufe der Lichtabhaltung allmählich der Norm oder manchmal übernormalen Werten Platz. Der Prozentsatz der Leukocytenarten zeigt dabei nichts Besonderes.

2) Die Erholung von der durch Aderlass hervorgerufenen Anämie verzögert sich deutlich bei der kurzdauernden Lichtabhaltung, bei der langdauernden dagegen nur geringfügig.

3) Die Erholung von der Aderlassanämie wird beim schild- 